\title{
0 tempo livre do trabalhador sob controle: comparação entre o Serviço de Recreação Operária (S. R. O.) e a Comunidade Nacional-Socialista Força pela Alegria (KdF)
}

\author{
The Free Time of the Worker Under Control: A Comparative Analysis \\ between the Serviço de Recreação Operária/Worker's Recreation Service
} (S. R. O.) and the National Socialist Community Force for Joy (KdF)

Elizabeth da Cunha Süssekind

Fundação Getúlio Vargas (FGV), Rio de Janeiro/Brasil Doutora em História, Política e Bens Culturais, Fundação Getúlio Vargas

Marcus Vinícius Macri Rodrigues

Universidade Federal do Rio de Janeiro (UFRJ), Rio de Janeiro/Brasil Doutorando em História Comparada, Universidade Federal do Rio de Janeiro marcusmacri@yahoo.com.br

\begin{abstract}
Resumo: O objetivo deste artigo é analisar, sob uma perspectiva comparativa, o primeiro ano de atividade do Serviço de Recreação Operária (S. R. O.), criado no final do ano de 1943, durante a ditadura de Getúlio Vargas, como órgão destinado a promover o lazer e a cultura do operário sindicalizado. Buscaremos contemplar a preocupação do governo Vargas com o tempo livre do operariado brasileiro, dentro do contexto do final do Estado Novo, utilizando matérias publicadas em periódicos, especialmente no jornal $A$ Noite. Contraporemos a política de Vargas à discussão sobre o tempo livre do trabalhador na Alemanha, antes e durante o regime nazista, especialmente com relação às atividades desenvolvidas pela Comunidade Nacional-Socialista Força pela Alegria KdF, que atuou durante o governo nazista (1933-1945).
\end{abstract}

Palavras-chave: Getúlio Vargas; Nazismo; Lazer; História Comparada; Classe Operária.

ABSTRACT: The aim of this article is to analyze, from a comparative perspective, the first year of activity of the Serviço de Recreação Operária/Worker's Recreation Service (S. R. 0.), created at the end of the year 1943, during Getúlio Vargas' dictatorship, as an organ intended to promote the leisure and culture of the Oper Unionized. We seek to contemplate the concern of the Vargas' government with the free time of the Brazilian workers within the context of the end of the new state, using articles published in periodicals, especially in the newspaper A Noite. We compare the Vargas' policy and discussion over the worker's free time with the German experience, before and during the Nazi regime, especially with regard to the activities developed by KdF, that acted during the National Socialist government (1933-1945).

KEYwoRDS: Vargas's Government; Nazism; Leisure; Comparative History; Working Class. 
No final do ano de 1943, durante a ditadura de Getúlio Vargas, foi criado o Serviço de Recreação Operária (S. R. 0.), como órgão destinado a promover o lazer e a cultura do operário sindicalizado. Em um contexto de grandes inovações na regulação do trabalho urbano no Brasil, a partir de 1930, com a promulgação de diversas legislações voltadas para o mundo do trabalho que seriam organizadas também em 1943 com a Consolidação das Leis Trabalhistas (CLT), nota-se a preocupação do governo Vargas com o tempo livre do operariado brasileiro no final do Estado Novo (1937-1945). No contexto da Segunda Guerra Mundial, em que o Brasil se colocava no campo como aliado de nações democráticas contra regimes fascistas, a criação de uma organização voltada ao controle do tempo livre do trabalhador poderia invocar uma identificação com iniciativas de regimes inimigos da nação naquele momento, como a organização alemã Kraft durch Freude - KdF (Comunidade Nacional-Socialista Força pela Alegria), que atuou durante o governo nazista (1933-1945) ou a organização italiana Il Dopolavoro, criada em 1925, pelo governo fascista de Benito Mussolini. Apesar disso, verifica-se, como veremos à frente, que o discurso do primeiro presidente do S.R.O. utilizava exemplos de organizações dos Estados Unidos e Inglaterra como inspiração para o serviço, além de adotar vocabulário que sugeria a criação de órgão como aquele foi uma iniciativa "democrática” em plena vigência do Estado Novo.

Buscaremos, utilizando matérias publicadas em periódicos, contrapor a política de Vargas, adotada com a criação do S. R. O., à discussão sobre o tempo livre do trabalhador na Alemanha, antes e durante o regime nazista, especialmente com relação às atividades desenvolvidas pela $K d F$, levando em consideração as colocações de Jürgen Kocka que, em Comparison and Beyond (2003),ำ que afirma que comparar em História significa discutir dois ou mais fenômenos históricos sistematicamente a respeito de suas similaridades e diferenças, de modo a se alcançar determinados objetivos intelectuais. Buscaremos assim realçar similitudes e divergências entre as duas iniciativas.

\footnotetext{
${ }^{1}$ KOCKA, Jürgen. Comparison and beyond, p. 39-44.
} 


\section{FORÇA PELA ALEGRIA: O TEMPO LIVRE CONTROLADO}

Em o "Tempo livre do trabalhador como problema sociopolítico", Hermann Giesecke aborda o esforço da burguesia alemã em tratar da questão do "tempo livre do trabalhador", suscitada pelo surgimento do descanso dominical e do tempo do nãotrabalho. ${ }^{2}$ Esse tempo passou a existir com a regulamentação da jornada máxima de 8 horas por dia, ainda no século XIX. 0 tempo livre era tratado como am eaça permanente de "embrutecimento dos costumes", como dispêndio de tempo excessivo em tavernas e risco de maior engajamento em questões políticas. A burguesia buscou, sem sucesso, uma "integração" dos trabalhadores nos valores de sua classe. No entanto, a cultura de massa suplantou esse projeto, ensejando novas abordagens para a questão.

Giesecke cita o esforço pelo "enobrecimento das recreações populares", voltado contra bares e literatura barata, visando a promoção da "reconciliação de castas e classes". Para tal, fomentaram eventos comuns, como excursões ou festas de fábricas, em que estratos sociais diferentes interagiriam, com a disposição dos "letrados" em agir como professores dos trabalhadores.

0 autor percebeu o esforço para se contrapor à social democracia, buscando-se estabelecer práticas onde "no negócio e na profissão deve imperar a disciplina e a subordinação rígidas; mas, para além do trabalho, nas horas de recreação, devemos procurar promover as relações entre os homens sempre de maneira natural, cordial e pacífica". ${ }^{3}$

0 autor aponta que o domingo livre gerava o problema de arrastar pessoas jovens e solteiras paras tavernas como única opção de divertimento, caso não utilizassem seu tempo livre em organizações esportivas, culturais ou religiosas. Essas questões apontavam que a sociedade alemã da época não estava preparada para lidar com a questão do tempo livre do trabalhador, com a burguesia buscando responder a essas situações com um viés contrário à social democracia.

\footnotetext{
${ }^{2}$ GIESECKE. Arbeiterfreizeit als sozialpolitisches Problem, p. 26-33.

${ }^{3}$ GIESECKE. Arbeiterfreizeit als sozialpolitisches Problem, p. 26-33. Livre tradução.
} 
Por sua vez, o autor mostra que, diferentemente das previsões iniciais, o tempo livre contribuiu para a despolitização dos trabalhadores, ensejando críticas de esquerdistas às atividades culturais e desportivas em que trabalhadores participavam. 0 temor do "embrutecimento dos costumes" também se revelou infundado, pois estava mais baseado em preconceitos motivados pelo desconhecimento da vida operária por parte da burguesia do que pela realidade.

No século XIX, as associações tornaram-se uma forma organizacional para atividades sociais de convivência, contando, algumas delas, com centenas de milhares de associados nas proximidades do início da Primeira Guerra Mundial. Verificou-se a competição entre associações operárias, burguesas e religiosas, opondo, por exemplo, ligas de cantores operários à "Liga dos Cantores Alemães", esta de orientação burguesa; ou a "associação dos ginastas alemães", ligadas ao Reich, à "Liga dos Ginastas Operários". Giesecke conclui que não se deve tomar o discurso das fontes burguesas como representativo da realidade do "problema do tempo livre" no período analisado e sugere que os "problemas" imaginados tornaram-se realidade no "entre guerras", quando essas associações se tornaram mais frágeis.

Elcio Cornelsen (2014) ${ }^{4}$ busca mostrar que o lazer sob o domínio nazista, durante boa parte do século XX, pós Segunda Guerra Mundial, foi visto como segmento apolítico da vida cultural alemã, panorama que mudou no pós-Guerra Fria, com diversos estudos sobre o fenômeno do totalitarismo. Citando Eckhard Jesse, assevera que o totalitarismo não se apoiaria apenas em repressão e terror, mas também em persuasão, mobilização e integração dos cidadãos. Deve-se focar atenção nos elementos de atração das massas para compreender o regime nazista em sua totalidade. Cornelsen afirma que o conceito de totalitarismo adotado por ele abrange tanto questões organizacionais quanto ideológicas, sociais, psicológicas ou comportamentais em estudos disciplinares, e buscou focar nas instituições estatais que instrumentalizaram o lazer dentro do sistema totalitário nacional socialista.

A criação de uma instituição que regulasse as políticas de lazer no período nazista fazia parte de uma política de "sincronização" (termo do jargão nazista,

${ }^{4}$ CORNELSEN. O lazer sob o jugo totalitário, p. 270-273. 
Gleichschaltung), uma política de intervenção no âmbito do trabalho, que buscava uniformizar e controlar todas as instituições públicas e sociais dessa área. Após a extinção das entidades sindicais, em 1933, foi criada a DAF (Deutsche ArbeitsFront/Frente Alemã do Trabalho), que abrangeria todas as categorias laborativas na Alemanha. Outra organização, a KdF (Kraft durch Freude / Comunidade NacionalSocialista "Força pela Alegria"), subordinada à DAF, para instrumentalizar o lazer e o esporte no âmbito trabalhista, foi instituída em novembro de 1933. Citando Frank Grube e Gerhard Richter, essa organização não era uma invenção nazista. Foi criada a partir de estruturas existentes no movimento sindical na República de Weimar e teve como precedente uma organização da Itália fascista, Il Dopolavoro, criada em 1925, pelo governo de Benito Mussolini. Suas atribuições eram promover políticas de higiene e saúde no âmbito das empresas, construir restaurantes, espaços de descanso e centros esportivos, todos mantidos por empresas e destinados a seus trabalhadores.

Determinou um aumento das férias anuais de três para doze dias por ano. Promoveu também uma ampla oferta de programas de lazer, culturais e esportivos. Sua estrutura organizacional dividia-se em cinco departamentos: 1) 0 "Serviço de Nacionalidade e Pátria", encarregado de organizar a participação de trabalhadores em eventos de caráter popular; 2) o "Serviço de Formação Popular Alemã" - que promovia cursos para adultos; 3 ) o setor "Beleza para o Trabalho", encarregado de fazer melhorias nas instalações de trabalho; 4) o "Serviço do Esporte"; 5) o "Serviço para Viagens, Passeios e Férias".

Cornelsen mostra que eram diversas as atividades promovidas pela KdF: idas a teatros, cinemas, concertos e exposições; passeios e práticas desportivas; danças folclóricas; exibição de filmes. Viagens subvencionadas para turismo. Esse último departamento teve relevância especial ao oferecer grande expansão da oferta de turismo para trabalhadores que, até então, não podiam se deslocar para fora de suas cidades de forma barata. Ofereciam até mesmo cruzeiros transatlânticos, cooperando para a popularidade dessa organização e do próprio regime nazista entre os trabalhadores alemães. 
O autor afirma que o intuito dessa política era organizar o tempo de descanso, relaxamento e lazer frente ao trabalho, no sentido de possibilitar aos trabalhadores a recuperação das forças físicas e psíquicas exigidas por suas funções, através da participação em atividades lúdicas. No entanto, não era esse o único intento do governo nazista: buscava-se evitar o ócio que produziria pensamentos "tolos, difamatórios e, por fim, criminosos". Naquele momento, o tempo livre não escapava ao controle total do estado alemão.

Em “A Comunidade Nazista 'Força pela Alegria': descanso para os trabalhadores - aumento de produção para o Estado", Claudia Schneider (2004) afirma que a Kraft durch Freude era a organização mais popular e eficaz do regime nazista, oferecendo amplo programa de descanso e diversão, sobretudo para o operariado, que, em grande parte, não tinha acesso a esses serviços. Ela reafirma a inspiração italiana do projeto. A repartição para o esporte era responsável pela educação física do povo alemão. Sua atuação tornou modalidades esportivas que dependiam de equipamentos caros acessíveis à maioria da população.

Tudo era subvencionado pela DAF e todos os trabalhadores pagavam taxas à organização. A repartição "Viagem, Excursão e Férias" se auto financiava e administrava $80 \%$ da movimentação financeira da comunidade KdF. Viagens curtas e até cruzeiros transatlânticos eram oferecidos. 0 cadastro era bastante burocrático e não era fácil ser contemplado com uma viagem cara.

As metas da KdF eram a supressão das diferenças sociais e a criação de uma grande comunidade popular alemã, na qual cada cidadão deveria ter os mesmos direitos à diversão e ao descanso. Tal sentimento de pertencimento era necessário para, segundo a autora, que as metas implícitas de Hitler fossem alcançadas. A educação física popular e a educação popular eram não menos importantes. 0 esporte deveria apurar a força de defesa das pessoas para "tarefas vindouras". 0 programa de entretenimento e as viagens eram elementos primordialmente de propaganda.

A autora afirma que o suposto programa altruísta e idealista da organização KdF era, por fim, uma estratégia apurada, no sentido de convencer o povo alemão da integridade dos planos de Hitler e, sobretudo, para levá-lo à "cooperação". A 
repartição "Viagem, Excursão e Férias" foi completamente dissolvida em fevereiro de 1943, e as demais repartições foram reagrupadas na "Repartição para Acompanhamento das Tropas da KdF e dos Empregados". 0 antigo programa de tempo livre tornou-se, finalmente, uma organização assistencial, que apoiou a guerra e fortaleceu a vontade de resistência do povo alemão.

A experiência alemã com o controle do tempo do trabalhador, até a derrota na Segunda Guerra Mundial, alcançou grande alcance junto à sua população e importante aspecto ideológico para o regime nazista, ao procurar controlar e "sincronizar" até o tempo do não-trabalho, para facilitar a consecução dos objetivos do governo nacional socialista. Ao analisar a realidade brasileira, cujo surgimento de um serviço voltado para a recreação dos trabalhadores é contemporâneo ao fim da experiência nazista, podemos verificar similitudes em algumas ações mas grandes diferenças nos discursos relativos aos objetivos da criação do S. R. 0 .

\section{DIFUNDIR CADA VEZ MAIS AS ATIVIDADES FÍSICAS E MORAIS ENTRE A CLASSE OPERÁRIA: o SERVIÇO DE RECREAÇÃo OPERÁRIA}

Nos últimos anos foram realizados diversos estudos sobre o Serviço de Recreação Operária, destacando-se a tese de doutorado de Ângela Bretas "Nem só de pão vive o homem: criação e funcionamento do Serviço de Recreação Operária (1943- 1945)" (2007), que aborda o processo de criação do Serviço e a influência das discussões sobre a questão do tempo livre do trabalhador brasileiro. Bretas, no artigo "O Serviço de Recreação Operária (1943-1945): uma experiência do governo Vargas no campo do não-trabalho", 5 também analisa as preocupações do Estado com relação ao tempo livre do trabalhador. 0 artigo de Elza Peixoto (2008) analisa a formação do S. R. O. com base em relatórios, entrevistas e na produção de Arnaldo Süssekind, reconhecido aqui como intelectual orgânico de classe. ${ }^{6}$ Aline Amoêdo Corrêa (2008) procura analisar comparativamente os dois serviços. Esses trabalhos têm em comum o uso de relatórios e entrevistas de Arnaldo Süssekind como fontes. A proposta deste artigo é

\footnotetext{
${ }^{5}$ BRETAS. Serviço de Recreação Operária: a singularidade de uma experiência (1943- 1945), p. 43-71.

${ }^{6}$ PEIXOTO. O serviço de recreação operária e o projeto de conformação da classe operária no Brasil, p. 115-140.
} 
FuLiA / UFMG - O tempo livre do trabalhador sob controle [...]

utilizar a fonte jornalística de forma a complementar o conhecimento sobre o tema. ${ }^{7}$

Utilizamos majoritariamente como fonte o jornal A Noite, fundado por Irineu Marinho em 1911, que funcionou até 1957. Atravessou diversas fases, sendo uma delas sua encampação estatal, no período do Estado Novo, ocorrida em 1940, e que durou até o seu fechamento. 0 verbete de Marieta Morais Ferreira sobre a trajetória do jornal cita Carvalho Neto, que argumentava que "a independência de A Noite incomodava o governo, e a alternativa era transformá-lo num 'diário oficial'... Assim, $A$ Noite, no decorrer dos 17 anos de encampação, transformou-se por decreto em órgão de elogio obrigatório a todos os governos" (2017).8 Utilizaremos também o jornal $A$ Manhã, do mesmo modo bastante alinhado com o governo de Vargas. Tânia Regina de Luca (2005) afirma que, ao utilizarmos periódicos como fontes de pesquisa, não devemos perder de vista que

[...] em vários momentos, a imprensa foi silenciada, ainda que por vezes sua própria voz tenha colaborado para criar as condições que levaram ao amordaçamento. 0 papel desempenhado por jornais e revistas em regimes autoritários, como o Estado Novo e a ditadura militar, seja na condição de difusor de propaganda política favorável ao regime ou espaço que abrigou formas sutis de contestação, resistência e mesmo projetos alternativos, tem encontrado eco nas preocupações contemporâneas, inspiradas na renovação da abordagem do político. ${ }^{9}$

A origem do esforço do governo Vargas em sistematizar a recreação remonta à edição do Decreto-Lei 4.298, de 14 de maio 1942, que tratava do recolhimento e aplicação do imposto sindical. No artigo $7^{\circ}$ desse decreto foi estabelecido que a renda da aplicação desse tributo por parte dos sindicatos de empregadores, empregados e profissionais liberais deveria ser aplicada em diversas atividades, que incluíam atividades culturais.

Em 25 de setembro de 1943, o jornal A Manhã edita uma nota sobre o processo de regulamentação de um serviço para o lazer operário:

\footnotetext{
7 Conf.: CORRÊA. A construção da modernidade e o controle do não-trabalho na sociedade brasileira: uma análise comparada do Serviço de Recreação Operária (S. R. O.) e o Serviço Social do Comércio (SESC).

${ }^{8}$ Conf.: FERREIRA. Dicionário histórico-biográfico da Primeira República.

${ }^{9}$ LUCA. História dos, nos e por meio dos periódicos, p. 129.
} 
Considerando que se faz mister difundir cada vez mais as atividades Físicas e morais entre a classe operária, facilitando-se lhe os meios de recreação em geral e prestando aos respectivos sindicatos a colaboração que se for necessária, resolve designar os assistentes técnicos deste Gabinete, Arnaldo Lopes Sussekind, Evaristo Morais Filho e Antônio da Conceição, como representantes dos empregados sindicalizados para, em comissão, sob a presidência do primeiro, elaboraram [sic] um projeto de portaria criando um serviço Especial junto à Comissão Técnica de Orientação Sindical, para atendimento daqueles objetivos. ${ }^{10}$

Em 06 de dezembro de 1943, o ministro do Trabalho edita a Portaria 68, que cria o Serviço de Recreação Operária - S. R. O., ao qual competia "difundir as atividades físicas e culturais entre os trabalhadores sindicalizados, facilitando e coordenando os meios de recreação em geral e prestando aos sindicatos a colaboração que for necessária". ${ }^{11}$ A Portaria estabelece que o S. R. 0. exerceria suas atividades nos setores culturais, no esportivo e no escotismo. De atribuição nacional, inicialmente foi organizado de modo direto no Distrito Federal, pois, nas demais unidades federativas a organização das atividades seria realizada por autoridades designadas pelo ministro do Trabalho, Indústria e Comércio.

No Jornal A Noite, de 31 de dezembro de 1943, foi publicada uma entrevista com o primeiro presidente do Serviço, Arnaldo Süssekind, que faz diversas colocações sobre o órgão:

O ser humano que trabalha e produz desenvolvendo a fortuna pública, necessita de entretenimento que o faça descansar por instantes das preocupações de sua oficina. E a recreação operária realiza bem o outro lado, também coletivo, para o qual foi criada. Aproxima os trabalhadores, faz com que se entretenham no convívio diário, estimulando entre eles um sadio processo de agremiação.

Consequentemente, o objetivo primordial do novo Serviço é o melhor aproveitamento social e individual das horas de folgas dos operários e de suas famílias, oferecendo-lhes possibilidades de praticar recreação saudável, de se congraçar na disputa esportiva ou num salão de diversões espirituais, fazendo-lhes esquecer, enfim, o ambiente profissional. Também ao filho do operário, seja ou não um aprendiz, será ministrada a mais aconselhável de todas as formas de recreação coletiva infantil: - o escotismo. ${ }^{12}$

\footnotetext{
${ }^{10}$ A MANHÃ. 25 set. 1943, p. 10.

${ }^{11}$ BRASIL. Diário Oficial da União, 08 dez. 1943, p. 18038.

${ }^{12}$ A NOITE. 31 dez. 1943, p. 9.
} 
Na matéria consta a afirmação de que centros de recreação operária seriam montados nos bairros de maior concentração de trabalhadores. E que a sociedade seria beneficiada por esses serviços através do cinema, rádio e do teatro operário, vistos como diversão e educação, e de música “acessível à mentalidade operária”, jogos de campo e salão. A reportagem afirma que outras vantagens adviriam do serviço: a facilitação da compreensão de seus direitos e deveres, melhoramentos da saúde do corpo e do espírito, sempre aumentando a disposição do trabalhador para seu ofício.

Süssekind, presidente do serviço recém-criado, ainda explica a razão de existir do S. R. O., segundo a visão do governo, apesar da CLT definir a percentagem do imposto sindical a ser aplicada pelos sindicatos em finalidades culturais e desportivas, era necessária a criação de um “órgão supervisor que facilitasse e coordenasse os meios de recreação em geral". 0 presidente do serviço faz uma afirmação que mostra as contradições no discurso do Estado varguista, em seus estertores:

Como manifestação democrática dos seus objetivos sociais, o Estado Nacional resolveu, assim, instituir esse aparelhamento central de orientação e estímulo à prática da Educação física e cultural, no qual tem participação direta um representante da massa proletária.

Nas grandes democracias, como os Estados Unidos e a Inglaterra, a recreação operária está, há vários anos em pleno funcionamento, sendo considerada, neste momento de intenso esforço de guerra, um dos fatores decisivos para a vitória na batalha da frente interna. Foi em boa hora, pois, que o Brasil criou o seu serviço de Recreação operária, com o qual afirma o sentido social de sua democracia.

Cabe alguma reflexão sobre essas últimas colocações: no contexto da Segunda Guerra Mundial, quando a ditadura varguista se colocava ao lado das democracias contra as ditaduras do Eixo, ficava evidente o descompasso entre a prática autoritária e centralista do Estado Novo e o discurso do S. R. O., onde a palavra "democracia" tem conotação altamente positiva no discurso de Süssekind.

No ano de 1944, observamos muitas reportagens nesse periódico sobre o S. R. O., desde a recepção dos trabalhadores à novidade, que comemoravam a possibilidade de poder inscrever seus filhos em grupos de escoteiros ou praticar esportes como a natação, como o esforço do S. R. O. em promover a alfabetização dos operários. 
Foram estabelecidos um programa e um concurso para a elaboração do material a ser usado nesse esforço. 0 Ministro do Trabalho editou a Portaria $\mathrm{n}$ o 18 , de 19 de abril de 1944, data das comemorações do aniversário natalício de Vargas, com a abertura de concurso para escolha de cartilha para alfabetização dos proletários. Na exposição de motivos, as justificativas para a medida foram a necessidade de elevar o “nível do proletariado brasileiro, cujo índice de conhecimento não é o desejável”, e que "se impõe ao Estado o dever de promover os meios de proporcionar ao povo recursos que permitam uma melhor vida, não só material como intelectual". ${ }^{13}$ No mesmo dia foi editada a Portaria no 19, que criava o programa de voluntariado da alfabetização operária, onde se afirma: “[...] o Ministro de Estado, considerando que o Serviço de Recreação Operária foi criado para difundir as atividades físicas e culturais entre os trabalhadores sindicalizados, facilitando e coordenando os meios de recreação em geral e prestando aos sindicatos a colaboração que for necessária"; e complementava afirmando que "o aludido serviço objetiva elevar, cada vez mais o nível de cultura do proletariado brasileiro, a fim de que a recreação espiritual possa realizar integralmente a sua alta finalidade". ${ }^{14}$ A Portaria 71, de 23 de dezembro de 1944, promulgou o resultado e determinou ao S. R. O. que promovesse a edição do trabalho vencedor, a gravação das aulas contidas nele, distribuindo os livros e os discos a todos os sindicatos de trabalhadores do Brasil.

O Jornal A Noite destaca a instalação do $1^{\text {o }}$ Centro de Recreação Operária, nas dependências do Carioca Sport Club, no bairro da Gávea, em publicação de 24 de fevereiro de 1944. No local, os operários teriam acesso a cinema, teatro, biblioteca e espaço para praticar "quase todos os sports". Após a cerimônia, houve apresentações de corais e uma partida de basquete entre trabalhadores. No discurso de inauguração, Süssekind novamente faz referência à democracia, e um adendo, onde argumenta que “o Serviço de Recreação Operária não interfere nos sindicatos, para a realização dos seus fins, como acontece em alguns países",15 e apenas coordenaria os meios de

\footnotetext{
${ }^{13}$ BRASIL. Ministério do Trabalho Indústria e Comércio. Diário Oficial da União, 24 abr. 1943.

${ }^{14}$ BRASIL. Ministério do Trabalho Indústria e Comércio. Diário Oficial da União, 24 abr. 1943.

${ }^{15}$ A NOITE. 24 fev. 1944, p. 2.
} 
FuLiA / UFMG - O tempo livre do trabalhador sob controle [...]

recreação. Nota-se claro esforço retórico de alinhamento com os países democráticos e afastamento de outras iniciativas semelhantes praticadas por nações fascistas. Nesse mesmo discurso, fica evidente que o Serviço é voltado exclusivamente ao trabalhador sindicalizado e aos seus familiares.

Uma segunda sede foi instalada no bairro do Méier. Inicialmente, seria localizada no Valim Esporte Clube, mas foi, de fato, instalada no Sport Club Mackenzie, em 28 de julho de 1944. Nesse centro, os trabalhadores poderiam ter acesso a uma filmoteca, biblioteca, teatro recreativo e campos para esportes em geral. 0 jornal $A$ Noite detalha que o funcionamento era intermitente. 0 centro da Gávea funcionava às terças e quintas-feiras à noite e domingos de manhã, e o do Méier, quartas e sextas à noite e domingos de manhã.

Vemos que as atividades do S. R. O. se utilizavam de infraestruturas existentes. Os Centros de Recreação foram objetos de diversas matérias, especialmente em ocasiões como festas para crianças, "Natal do trabalhador sindicalizado" e comemorações de fim de ano. Cabe reproduzir uma nota do jornal $A$ Noite de 04 de abril de 1945, sobre os fatos ocorridos no dia 31 de dezembro de 1944, quando houve a festa de encerramento de atividades no C. R. O. do Meier:

Linda festa esportiva no Centro de recreação operária do Méier encerrando as suas atividades esportivas do ano de 1944, o serviço de recreação operária do Ministério do Trabalho Indústria e Comércio, que muito vem se distinguindo pelas suas brilhantes iniciativas em prol, não só da cultura física, como também do desenvolvimento intelectual dos filhos dos trabalhadores sindicalizados, fez realizar, na manhã de domingo, dia 31 de dezembro p. p. [sic], uma bela festa esportiva. A solenidade, que se revestiu de grande brilho, teve lugar às 9 horas, no centro de recreação do Méier, à rua Dias da Cruz, 561, obedecendo ao seguinte programa: desfile de abertura, Hino Nacional e hasteamento da bandeira brasileira; exercícios com bastões; corrida de "medicine ball"; cabo de guerra; briga de galos (menores); pirâmides em trios; basketball. Torneio relâmpago com tempos de seis minutos; volley ball gigante.

O S. R. O. também organizou passeios para trabalhadores. A ilha de Brocoió, na baía de Guanabara, adquirida pela administração do Distrito Federal, recebeu uma excursão de trabalhadores, relatada pelo jornal A Noite, de 26 de junho de 1944 . A 
matéria, além de tecer os costumeiros elogios ao governo, faz a afirmação de que essa iniciativa era prova "de compreensão recíproca entre governo e o povo concorre de modo bastante expressivo para solidificar os elos de simpatia popular para com os supremos dirigentes da nação". Na programação constaram passeios pela ilha, jogos de volleyball, de peteca, futebol e banhos de mar, bem como exibição de um filme de longa-metragem, e outras atividades lúdicas, como corrida de sacos e esquetes. A edição de 18 de junho de 1944 informou que o passeio era gratuito, sendo a única condição exigida a "carteira sindical".

Outras atividades foram destacadas pelo jornal: o concurso da "Canção do Trabalhador Brasileiro" que, em julho daquele ano premiou uma canção que exaltava "o Brasil Trabalhista", e "a alegria das conquistas alcançadas sem as crises sangrentas que seus irmãos de outras terras suportaram". Campeonatos intersindicais de futebol foram organizados e muitas vezes serviram de preliminares para eventos políticos de massa do governo Vargas. A matéria "A estiva venceu o 'Fla Flu' sindical" mostra uma dessas partidas. As apresentações do "Teatro do Trabalhador Brasileiro" ganharam boa cobertura jornalística, sendo frequentes as referências às apresentações no Teatro Fênix.

0 escotismo recebeu muito destaque dentro do S. R. O., sendo visto até mesmo como inspiração para a criação do Serviço. Diversos grupos de escoteiros foram organizados e realizaram atividades como os acampamentos na ilha de Brocoió, em fevereiro de 1945. Antes, em 22 de setembro de 1944, o jornal A Noite relatou uma homenagem feita pelos escoteiros a Getúlio Vargas. Cada sindicato tinha o seu grupo de escoteiros, nomeado ora com grandes referências da cultura e história do Brasil, ora com nomes de membros do Governo Vargas.

\section{CONCLUSÃo}

Jurgen Kocka, em Comparison and Beyond (2003), ${ }^{16}$ afirma que comparar em História significa discutir dois ou mais fenômenos históricos sistematicamente a respeito de suas similaridades e diferenças, de modo a se alcançar determinados objetivos

\footnotetext{
${ }^{16}$ KOCKA, Jürgen. Comparison and beyond, p. 39-44.
} 
intelectuais. A abordagem comparativa pressupõe que as unidades de comparação possam ser separadas umas das outras, sendo casos independentes, reunidos analiticamente através de perguntas sobre as similaridades e diferenças entre eles. Heuristicamente, a abordagem comparativa permite identificar questões e problemas que poderiam, de outro modo, se perder e negligenciar, ou apenas não inventar. Descritivamente, a comparação histórica ajuda a esclarecer os perfis de casos singulares, frequentemente de um único caso, ao contrastá-los com outros.

A comparação entre as iniciativas da KdF e do S. R. O. mostra preocupação dos governos em lidar com a questão do tempo livre do trabalhador e a visão do Estado como responsável direto pela implementação de políticas do gênero, mesmo que, no caso brasileiro, venham disfarçadas como papel de "coordenação". Ambos os serviços se utilizaram de infraestruturas existentes para organizar suas atividades: no caso nazista a expropriação dos bens dos sindicatos favoreceu as atividades e, no Brasil, as instalações de clubes já existentes servia para a montagem de centros de recreação ou de realização de eventos, como partidas de futebol ou passeios.

0 uso do teatro e do cinema favorecia a divulgação de ideologia, ou, na pior das hipóteses, não prejudicava o esforço de propaganda, pois eram selecionados apenas filmes considerados "adequados". Percebe-se que a preocupação com a questão laboral estava mais presente na Alemanha, na organização "Beleza para o Trabalho", com intervenções diretas nos locais do trabalho, enquanto que, no Brasil, voltava-se mais atenção para a recuperação física do trabalhador e aos esforços de aumentar o nível cultural do operariado brasileiro.

É possível perceber que ambos os órgãos se esforçaram em fortalecer os laços entre os regimes e a população, através da concessão de benesses aos trabalhadores, em esforço de propaganda que visava mostrar "boas intenções para o trabalhador" por parte dos governos dos dois países.

No entanto, cabe ressaltar que, no caso brasileiro, houve preocupação em estabelecer diferenciações claras entre o S. R. O. e iniciativas similares, como as da KdF ou do Dopolavoro. 0 presidente do órgão em mais de um discurso enalteceu o caráter "democrático" do Serviço, deixando claro que não havia intervenção 
governamental nos sindicatos, apenas uma coordenação dos esforços. Buscou também estabelecer semelhanças entre os programas voltados para o lazer dos trabalhadores dos Estados Unidos e da Inglaterra. Em momentos posteriores, quando a ditadura varguista já havia caído, Süssekind faz referências às influências das normas da OIT e da Rerum Novarum como inspirações para o Serviço de Recreação Operária, embora não tenhamos encontrado qualquer referência a isto nas fontes analisadas, o que demandaria mais tempo e a ampliação do número de materiais a serem consultados. É certo que, no contexto em que lutava contra as potencias do Eixo, não interessava ao governo brasileiro estabelecer qualquer ligação entre os governos que enfrentava em campo de batalha. 0 uso da palavra "democrático" chama atenção, vinda de um representante de um regime que abrigava entre seus ideólogos diversos simpatizantes de países fascistas. 0 esforço em defender as conquistas trabalhistas, refutando influências fascistas era evidente por parte de Süssekind, após a queda do primeiro governo Vargas, tanto ao se referir ao S. R. 0., como à própria Consolidação das Leis Trabalhistas - CLT.

Vemos que o esforço de organizar o lazer do trabalhador operário brasileiro foi muito mais modesto em relação ao feito na Alemanha nazista, em virtude de falta de infraestrutura prévia voltada para o lazer. E, ainda, pelo caráter aparentemente menos voltado para o controle que, no caso alemão, estava inserido no contexto de "sincronização" típica daquele governo totalitário, algo que a ditadura de Vargas não chegou a executar. Deve-se ter em mente que, no período em que o S. R. O. estava sendo construído, as "máscaras" das iniciativas totalitárias do regime nazista já haviam caído e que a entrada do Brasil na Segunda Guerra Mundial, ao lado de potências democráticas, acarretou conflitos entre a prática autoritária, a defesa no campo de batalha e o discurso de valores opostos aos interesses do governo do Estado Novo. 


\section{REFERÊNCIAS}

A MANHÃ. Rio de Janeiro, 25 set. 1943, p. 10.

A NOITE. Rio de Janeiro, $31 \mathrm{dez} .1943$, p. 9.

A NOITE. Rio de Janeiro, 10 fev. 1944, p. 16.

A NOITE. Rio de Janeiro, 24 fev. 1944, p. 2.

A NOITE. Rio de Janeiro, 28 abr. 1944.

A NOITE. Rio de Janeiro, 18 jul. 1944, p. 12.

A NOITE. Rio de Janeiro, 30 ago. 1944, p. 11.

A NOITE. Rio de Janeiro, 19 set. 1944, p. 7.

A NOITE. Rio de Janeiro, 22 set. 1944, p. 2.

A NOITE. Rio de Janeiro, 15 fev.1945, p. 10.

BRASIL. Decreto-lei no 4298, maio 1942. Disponível em: <https://bit.ly/2J0221L>. Acesso em: 10 nov. 2017.

BRASIL. Ministério do Trabalho Indústria e Comércio. Portaria n. 18, 19 abr. 1943. Diário Oficial da União, 24 abr. 1943. Seção I.

BRASIL. Ministério do Trabalho Indústria e Comércio. Portaria n. 68, 06 dez. 1943. Diário Oficial da União, 08 dez. 1943, p. 18038.

BRASIL. Ministério do Trabalho Indústria e Comércio. Portaria n. 71, 23 dez. 1944. Diário Oficial da União, 23 dez. 1943. Seção I.

BRETAS, Ângela. Serviço de Recreação Operária: a singularidade de uma experiência (1943-1945). In: BRETAS, Ângela ; Alves Júnior, E. de D.; Melo, V. A. (org.). Lazer e cidade: reflexões sobre o Rio de Janeiro. Rio de Janeiro: Shape, 2008, p. 43-71.

CORNELSEN, Elcio. O lazer sob o jugo totalitário. I Congresso Brasileiro de Estudos do Lazer: o Lazer em debate. Coletânea. Belo Horizonte: EEFFTO/UFMG, 2014, p. 270-273.

CORRÊA, Aline Amoêdo. A construção da modernidade e o controle do nãotrabalho na sociedade brasileira: uma análise comparada do Serviço de Recreação Operária (S. R. O.) e o Serviço Social do Comércio (SESC). In: XIII ENCONTRO DE HISTÓRICA ANPUH-RIO, 2008, Rio de Janeiro. Anais eletrônicos. Disponível em: <https://bit.ly/2QkTfvS>.

DOU, 13 set. 1944, p. 15902, seção I.

FERREIRA, Marieta de Morais. Noite, A. In: ABREU, Alzira Alves de. Dicionário histórico-biográfico da Primeira República. Rio de Janeiro: Editora FGV, 2009. Disponível em: <https://bit.ly/2SzsGj1>. Acesso em: 19 nov. 2017. 
FEREIRA, Marieta de Morais. Noite, A. In: ABREU, Alzira Alves de. Dicionário histórico-biográfico da Primeira República. Rio de Janeiro: Editora FGV, 2009. Disponível em: <https://bit.ly/2SzsGj1>. Acesso em: 19 nov. 2017.

GIESECKE, Hermann. Arbeiterfreizeit als sozialpolitisches Problem. In: GIESECKE, Hermann. Leben nach der Arbeit: Ursprünge und Perspektive der Freizeitpädagogik. München: Juventa-Verlag, 1983, p. 26-33.

KOCKA, Jürgen. Comparison and beyond. History and Theory, v. 42, n. 1, p. 3944, fev., 2003. Tradução de Maria Elisa da Cunha Bustamante.

LUCA, Tânia Regina de. História dos, nos e por meio dos periódicos. In: PINSKY, Carla Bassanezi; et al. (org.). Fontes Históricas. São Paulo: Contexto, 2005, p. 111-153.

PEIXOTO, Elza. O serviço de recreação operária e o projeto de conformação da classe operária no Brasil. Pro-Posições, v. 19, n. 1, p. 115-140, jan.-abr. 2008.

SANTOS, Ângela Bretas Gomes dos. "Nem só de pão vive o homem": criação e funcionamento do Serviço de Recreação Operária (1943-1945). Tese (Doutorado). Faculdade de Educação, Universidade Estadual do Rio de Janeiro, 2007.

SCHNEIDER, Claudia. Die NS-Gemeinschaft, "Kraft durch Freude", 02 nov. 2004. Disponível em: <https://bit.ly/2wLqMoc>. Acesso em: 21 fev. 2018.

Recebido para publicação em: 05 maio 2018. Revisões requeridas em: 26 dez. 2018. 